\title{
A LÓGICA DA FICÇÃO NO “TRATADO” DE HUME
}

\author{
Pedro Jonas de Almeida* \\ pjonas.almeida@gmail.com
}

RESUMO No Livro I, parte IV, do "Tratado da natureza humana", Hume desenvolve aquilo que vamos chamar de lógica da ficção. Não se trata de um simples erro da imaginação enquanto fantasia, mas de uma propensão a criar ideias, entidades e objetos a partir das percepções presentes na mente. O que resulta dai é um sentido rico e novo de fiç̧ão que permite a Hume desenvolver uma história natural da filosofia, descrevendo a gênese inevitável de conceitos metafísicos. Partindo de uma inspiração kantiana, iremos abordar esse tema ressaltando as semelhanças e diferenças entre as ficções naturais e a ilusão transcendental.

Palavras-chave Ficção, Fantasia, Erro, Ilusão Transcendental.

ABSTRACT In Book I, part IV, of the "Treatise of Human Nature", Hume develops what we will call logic of fiction. It is not the case of a mere error of imagination as fancy, but a tendency to feign ideas, entities and objects from the perceptions in the mind. The result is a rich and new sense of fiction that allows Hume to establish a natural history of Philosophy, describing the unavoidable genesis of metaphysical concepts. From a Kantian point of view, we will approach this subject by highlighting the similarities as well as the differences between the natural fictions and the transcendental illusion.

Keywords Fiction, Fancy, Error, Transcendental Illusion.

* Universidade Federal de Goiás (UFG), Regional Goiás. O presente artigo foi parcialmente escrito quando contávamos com uma bolsa DAAD/CAPES para a realização de um doutorado sanduíche na Alemanha, de dezembro de 2013 a fevereiro de 2015. Artigo recebido em 03/09/2013 e aprovado em 21/10/2014.

KRITERION, Belo Horizonte, nº 134, Ago./2016, p. 455-469 


\section{I}

Se ser é ser percebido por uma mente que percebe, não basta que essa mente seja pensada como finita. Se fosse esse o caso, não teríamos como impedir que, quando essa mente finita deixasse de perceber, se seguisse a aniquilação de tudo o que há. Sabe-se como o Deus de Berkeley irá contornar esse problema. Deus é aquela mente infinita criadora das percepções-ideiasobjetos e cuja linguagem é o próprio mundo sensível. Ora, essa hipótese é mesmo necessária? Hume sente que não. Parece mesmo que Hume experimentou, diante da filosofia de Berkeley, aquela impressão de que ela é irrefutável sem conseguir convencer. Talvez uma reformulação do problema permita introduzir outra hipótese, quem sabe mais frutífera. Não mais perguntar pela legitimidade da distinção entre ideia-percepção e objeto da percepção. De preferência, formular essa: de que modo somos levados a crer que há objetos independentes das percepções e, ao contrário delas, dotados de existência contínua? Ou, em seus próprios termos: "perguntar que causas nos induzem a crer na existência de corpos" ${ }^{1}{ }^{1} \mathrm{E}$ quanto a investigar se há ou não objetos e corpos independentes de uma mente que percebe? É inútil, diz Hume. Foi reformulando assim a questão de Berkeley que Hume pôde introduzir uma noção nova e rica de ficção, diferente do mero erro ou confusão, e que passa a desempenhar uma função que ultrapassa o local do texto onde ela faz sua aparição no "Tratado da Natureza Humana", revelando-se até no campo da atividade política e jurídica.

Há uma ficção que se distingue da crença do ponto de vista da vivacidade com que uma ideia é concebida. "Podemos, em nossa compreensão, juntar a cabeça de um homem ao corpo de um cavalo, mas não está em nosso poder acreditar que um tal animal tenha alguma vez realmente existido". ${ }^{2}$ Usada nesse sentido, a ficção pode ser aproximada dos erros e pré-conceitos que impedem a mente de ser bem exercida no campo do conhecimento científico. Para regular seus efeitos nocivos sobre o entendimento humano, Hume desenvolve uma teoria das regras gerais corretivas. É preciso estabelecer "algum processo intelectual e alguma reflexão sobre o que se observou"3 para operar alguma demarcação no campo da vivacidade das ideias e poder distinguir a crença da ficção com algum sucesso. Mas não é esse o sentido de ficção que nos

1 "Tratado da Natureza Humana", I, IV, ii, §1. Daqui em diante, citado T. seguido por Livro, Parte, Seção e Parágrafo. Usamos a tradução de Déborah Danowski, edição UNESP.

2 "Investigação sobre o entendimento humano", 5, 2, § 10. Daqui em diante, citado IEH, seguido por Seção, Parte e Parágrafo. Usamos a tradução de José Oscar de Almeida Marques, edição UNESP.

3 IEH. $5,1, \S 5 n$. 
interessa. Na parte IV do Livro I do "Tratado da natureza humana", Hume isola uma ficção que pertence mais ao domínio das propensões naturais, inevitáveis e incorrigíveis, do que ao domínio do erro corrigível. Melhor ainda, a ficção, tomada nesse novo sentido, parece induzir ao erro, colocarnos naquela situação do visionário que crê em seus sonhos e devaneios como se fossem visões autênticas. "A identidade que atribuímos à mente humana é apenas fictícia, e de um tipo semelhante à que atribuímos a vegetais e corpos animais". "Eis aí um caso em que a ficção é uma propensão tão forte que, antes de nos darmos conta, leva-nos a crer que tal identidade é um fato estabelecido sobre a natureza da mente humana.

É assim que criamos a ficção da existência contínua das percepções de nossos sentidos, com o propósito de eliminar a descontinuidade; e chegamos à noção de uma alma, um eu e uma substância, para encobrir a variação. Mas podemos observar além disso que, mesmo quando não criamos tal ficção, nossa propensão a confundir a identidade com a relação é tão forte que tendemos a imaginar alguma coisa desconhecida e misteriosa conectando as partes, além da relação. [...] Quando atribuímos identidade, em um sentido impróprio, a objetos variáveis e intermitentes, nosso erro não se limita à maneira como nos exprimimos; ao contrário, comumente se faz acompanhar de uma ficção, seja de alguma coisa invariável e ininterrupta, seja de algo misterioso e inexplicável, ou ao menos de uma propensão para tais ficções. ${ }^{5}$

Essa propensão para a ficção mostra-se na história da filosofia que Hume apresenta e desenvolve nessa parte do "Tratado". Essa história natural da filosofia pretende estabelecer a gênese dos conceitos metafísicos do passado. Será essa propensão para a ficção que estará na base dessa gênese dos conceitos metafísicos. A metafísica, esse discurso abstruso, fornece o registro dos devaneios do homem, desse "ser que se vangloria com o nome de racional". ${ }^{6}$ Ou seja, trata-se de mostrar como os conceitos metafísicos são gerados por operações frívolas da fantasia, sem que isso queira necessariamente dizer que tais conceitos sejam também frívolos. Isso porque as causas que geram esses conceitos também nos induzem a crer neles. Daí não haver mais como, aqui, distinguir a ficção e a crença. Esses conceitos serão considerados frívolos apenas do ponto de vista do exercício do entendimento na investigação seja da natureza seja da natureza humana - ponto de vista normativo. Uma ideia

4 T. I, IV, vi, § 15.

$5 \quad T, \mathrm{I}, \mathrm{IV}, \mathrm{vi}, \S 6$ e 7.

6 "História natural da religião", Seção 15, p. 125. Henry Allison também sugere que essa parte do "Tratado" contém a história natural da filosofia de Hume. Para Allison, essa analogia ainda permite pensar em uma função terapêutica dessa parte. A metafísica, para Hume, é fonte de neurose e melancolia, exigindo uma postura filosófica específica como remédio - um ceticismo mitigado. Voltaremos à questão terapêutica mais adiante. Cf. Allison, "Custom and reason in Hume". Capítulo 10. 
gerada pela propensão natural para a ficção será dita trivial ou não conforme o fim a que ela for subordinada. Do ponto de vista do conhecimento, ela é quase sempre nociva. Porém, dos pontos de vista estético e moral, ela pode não ser inútil.

\section{II}

A atitude de Hume diante dessa propensão para a ficção não é uniforme. Na parte IV do Livro I, ele tende a afirmar, por um lado, que a metafísica está mais próxima das descrições que os poetas fazem das punições de Sísifo ou Tântalo. É difícil, diz Hume, "imaginar tormento maior que a busca voraz de algo que para sempre nos escapa; e sua busca lá onde é impossível que possa existir". 7 Por outro lado, essas ficções não apenas são naturais e inevitáveis, como passam a desempenhar o papel de organizadoras da experiência, gerando, por exemplo, a ideia de mundo - somos levados por elas "a ver o mundo como algo real e duradouro, e que preserva sua existência mesmo quando não mais presente à minha percepção". ${ }^{8}$ Além disso, no Livro III, as ficções, apesar da origem frívola, se tornam assunto sério. As regras gerais ou as instituições político-sociais e jurídicas não devem ser confiadas, no que se refere a sua gênese, "às falazes deduções de nossa razão - que é lenta em suas operações". ${ }^{9}$ O filósofo-historiador percebe que a credibilidade das instituições e práticas sociais ficaria ameaçada se sua gênese histórica dependesse dessas lentas operações do entendimento ou da razão. A crença na legitimidade dessas instituições precisa ser rapidamente estabelecida e introjetada na mente dos cidadãos ou súditos. Do ponto de vista do entendimento ou da razão, há, em qualquer formação social, regras gerais bem irracionais, isto é, geradas na e pela fantasia, que não deixam de reclamar obediência. Dito de outra forma, o lado delirante da natureza humana contribui para o desenvolvimento de uma série de convenções e instituições sociais.

Porém, para não extrapolar o espaço deste texto, vejamos esse lado delirante emergindo na história natural da filosofia de Hume. Vejamos como há muitas descobertas que podem ser úteis quando feitas "com base em uma crítica das ficções da filosofia antiga referentes a substâncias, formas substanciais, acidentes e qualidades ocultas - que, por mais irracionais e caprichosas, possuem uma conexão íntima com os princípios da natureza 
humana". ${ }^{10}$ Eis aí uma primeira lista dos conceitos gerados no interior da história da metafísica. Sabe-se que no mundo de Hume só se pode garantir a existência de percepções diferentes, separáveis e distinguíveis entre si. A crítica das ficções só possui sentido quando se parte desse pressuposto filosófico. O dado não é simplesmente dado para uma filosofia; ele já vem contaminado pelos pressupostos a partir dos quais é lido e interpretado por ela. Sendo assim, como é possível que haja "UMA coisa, que continua a MESMA ao longo de alterações bastante consideráveis", ${ }^{11}$ se tudo o que temos são percepções diferentes, separáveis e distinguíveis entre si? O que é um melão ou um pêssego senão as cores, os sabores, as formas e outras qualidades sensíveis combinadas pela associação ou relação mais ou menos estreita entre elas que se dá na mente?

A definição que pode ser dada desse gênero de ficção é a seguinte: tendência a tomar uma transição fácil entre as percepções na mente por uma percepção de um objeto contínuo e independente da mente. Isto é, pensar a gênese do conceito de substância, por exemplo, consiste em mostrar como gradativamente se passa (a) do "progresso suave do pensamento", ou de percepções na mente, que tende a nos fazer atribuir uma identidade à sucessão descontínua de qualidades sensíveis (um melão, um pêssego) para (b) "uma mudança considerável" de perspectiva ou ponto de vista (o girar dos olhos, por exemplo), cujo efeito imediato é a quebra do "progresso do pensamento" e o nascimento concomitante da ideia de diversidade (ao girar os olhos, o melão já não pode ser o MESMO) e, finalmente, para (c) o aparecimento de uma tensão ou contradição entre "a" e "b", cuja resolução ou superação compete à imaginação que "tende a fantasiar algo desconhecido e invisível, que supõe continuar o mesmo ao longo dessas variações". ${ }^{12}$ Esse algo desconhecido e invisível ganha, então, um nome de batismo: substância, e passa a circular livremente na filosofia sem que sua origem gratuita levante suspeita. Mais importante ainda é que a passagem de "a" até "c" é uma propensão inevitável e natural. Esse modelo explicativo de natureza genético-psicológico tende a se manter ao longo da parte IV do Livro I: trata-se sempre de compreender como o pensamento de percepções descontínuas e dependentes de uma mente que 
percebe pode dar origem, por um deslize difícil de observar, ao pensamento de algo idêntico, seja substância material, mental ou divina. ${ }^{13}$

É na seção ii que Hume aponta para um deslize do pensamento como origem da ficção ou ilusão de mundo: "o pensamento desliza ao longo da sucessão com a mesma facilidade com que considera um objeto único; por isso confunde a sucessão com a identidade" (§ 34). Essa sucessão é o "progresso suave e ininterrupto da imaginação que acompanha a visão de um mesmo objeto invariável". Ou seja, tomamos essa progressão suave e fácil "que produz pouca alteração na mente" pela mesmidade de um suposto objeto. Mais adiante, no $\S 36$, ele repete que "a passagem suave da imaginação pelas ideias das percepções semelhantes faz que atribuamos a elas uma identidade perfeita”. Deslizamos da semelhança para a identidade. O hábito, esse princípio da natureza humana, não é por si só capaz de explicar a gênese dessas ficções, sendo preciso pensar na "cooperação de alguns outros princípios" constantes - a fantasia. É assim que a ideia de Mundo só pode nascer da fantasia.

[...] nenhum grau de regularidade em nossas percepções pode jamais servir de fundamento para inferirmos um grau maior de regularidade em alguns objetos que não percebemos; isso suporia uma contradição, a saber, um hábito adquirido de algo que nunca esteve presente à mente. [...] como todos os raciocínios sobre questões de fato surgem unicamente do costume, e como o costume só pode resultar de percepções repetidas, a extensão do costume e do raciocínio para além das percepções nunca poderia ser um efeito direto e natural da repetição e da conexão constantes, devendo antes, surgir da cooperação de alguns outros princípios. ${ }^{15}$

A fantasia se torna, assim, uma espécie de máquina de costurar o mundo. Sabemos que as percepções são descontínuas, separáveis e discerníveis entre si, mas a fantasia, diz Hume, é atravessada por uma espécie de inércia, ou seja, por uma propensão de preencher as lacunas que observamos entre as percepções. Na seção v, Hume afirma que há uma qualidade da natureza humana que pode ser enunciada assim: "quando determinados objetos estão unidos

13 A seção 11 da IEH pretende "investigar até que ponto a religião pode ser estabelecida sobre princípios da razão" (§ 10). Os resultados dessa investigação são aprofundados nos "Diálogos sobre a religião natural" e na "História natural da religião", ainda que nesta última de um ponto de vista mais antropológico e histórico. Aqui basta assinalar a insidiosa presença da fantasia e de suas tendências na religião sob suas diversas formas - monoteísmo, politeísmo, deísmo, teísmo, etc. Na seção 2 da IEH, precisamente sobre a origem das ideias, a ideia de Deus, "no sentido de um Ser infinitamente inteligente, sábio e bondoso, surge da reflexão sobre as operações de nossa própria mente e do aumento ilimitado dessas qualidades de bondade e sabedoria" (§ 6). A fantasia é quem aumenta essas qualidades ilimitadamente.

14 T. I, IV, ii, § 21

15 Ibid. 
por uma relação qualquer, temos uma forte propensão a acrescentar a eles uma nova relação, a fim de completar a união". ${ }^{16}$ A fantasia tende a fortalecer as conexões entre as percepções, deslizando de uma semelhança para uma identidade perfeita e completa entre elas. A mente como suporte espiritual das percepções é pensada como simples quando "fantasiamos a existência de um princípio de união como suporte dessa simplicidade", primeiro nos melões e pêssegos e, por um deslize imperceptível, na própria mente assim reificada. A natureza humana possui uma tendência não apenas a generalizar, mas de estender generalizações o mais longe possível e de supor que há ordem no mundo mesmo quando aparentemente evidências contrárias ameaçam esta ordem. Dito de outra forma, a "ilusão é singularmente mais grave quando ela mesma faz parte da natureza humana, isto é, quando o exercício ou a crença ilegítima é incorrigível, inseparável das crenças legítimas, indispensáveis para sua organização". ${ }^{17}$

A atitude ambígua de Hume diante de sua própria história natural da filosofia aparece com todo vigor e dramaticidade na conclusão do Livro I. Isso ocorre quando abandonamos o ponto de vista da gênese, da história e da descrição, e adentramos o terreno normativo da justificativa e da legitimação. Após examinar, ao longo da parte IV do Livro I, os diversos sistemas filosóficos, tanto sobre o mundo intelectual como sobre a natureza ou universo, e flagrar o nascimento dos conceitos metafísicos a partir da fantasia, Hume se interroga: "a questão é: até que ponto devemos ceder a essas ilusões"? ${ }^{18}$ Até que ponto essas ficções podem ser reguladas pelas regras gerais corretivas que nos permitem dosar a crença em proporção à evidência? Ou até que ponto se pode manter a distinção, na imaginação, entre "os princípios permanentes, irresistíveis e universais" e os "princípios varáveis, fracos e irregulares"? ${ }^{19}$ Os voos da imaginação ameaçam apagar a distinção entre crença razoável e os devaneios mais alucinados da fantasia. Podemos até perdoar, diz Hume, as crianças por cederem à "notável inclinação a atribuir aos objetos externos as

16 T. I, IV, v, § 12.

17 Cf. Deleuze, Gilles. "Hume", p. 215. Esse texto de Deleuze, de 1972, possui o mérito de assinalar esse sentido original de ficção que estamos investigando. Hume, diz Deleuze, substitui "o conceito tradicional de erro pelo conceito de delírio ou ilusão, segundo o qual há crenças, não falsas, mas ilegítimas, exercícios ilegítimos das faculdades, funcionamentos ilegítimos das relações. Kant, também aí, deverá alguma coisa de essencial a Hume. Não estamos ameaçados pelo erro, mas, o que é muito pior, estamos imersos no delírio". Parece-nos, entretanto, que aqui há menos influência de Hume sobre Kant do que uma leitura kantiana de Hume, que não deixa de ser interessante e original. O livro já citado de Henry Allison possui, à sua maneira, a mesma inspiração. Trata-se, segundo o subtítulo do livro de Allison, de fazer uma leitura kantiana do primeiro livro do "Tratado". Quanto a nós, não há como escamotear o fato de que o título que escolhemos para este artigo é de inspiração kantiana.

18 T. I, IV, vii, $\S 6$.

19 T. I, IV, iv, § 1. 
mesmas emoções que [observam] em si [próprias]". A fantasia também possui essa qualidade de projetar as percepções da mente nos objetos externos. Mas que justificativa podem dar os filósofos peripatéticos quando inundam a natureza com suas vãs noções de "simpatias, antipatias e horror ao vácuo"?"20

Ora, a história natural da filosofia não mostra justamente que essas noções são geradas inevitavelmente? Porém, quando se introduz o ponto de vista normativo, surge a questão: a quais delas daremos nosso assentimento e a quais não? No momento mais agudo do vai e vem de questões que anima a seção vii, o filósofo se desespera: "não nos resta escolha, portanto, senão entre uma falsa razão e razão nenhuma". Sim, pois uma razão que acolhesse todas as "triviais sugestões da fantasia" seria uma falsa razão. Mas, em contrapartida, uma razão ou um entendimento que agisse "sozinho e de acordo com seus próprios princípios mais gerais, destrói-se a si mesmo, sem deixar subsistir o menor grau de evidência em nenhuma proposição, seja na filosofia, seja na vida comum". ${ }^{21}$ Faltaria ao entendimento, nesse caso, a vividez que circula pela imaginação como por um circuito energético. ${ }^{22}$

Para Hume, essas questões normativas não se resolvem pela especulação de gabinete, mas pela atividade social temperada por um ceticismo moderado. Já que a paixão de curiosidade irá continuar nos animando a sempre investigar "os princípios morais do bem e do mal, a natureza e o fundamento do governo, e a causa das diversas paixões e inclinações que [nos] movem e governam", ${ }^{23}$ cabe-nos conduzir essas investigações com a consciência de sua fragilidade ou de seu caráter sempre provisório e renovável. Ou seja, o ceticismo moderado é a consciência da ausência de fundamento último, do princípio explicativo primeiro e definitivo de todas as coisas, sem que a consciência desse limite, ou esse saber de um não-saber, represente a abolição da própria atividade de investigar. "O verdadeiro cético desconfiará tanto de suas dúvidas filosóficas como de sua convicção filosófica; e jamais, em virtude de nenhuma delas, recusará qualquer satisfação inocente que se ofereça". ${ }^{24}$ Contra os desesperos de um Sísifo ou de um Tântalo, enfim, há o consolo a seguir: "tão logo nos damos conta da impossibilidade de satisfazer um desejo, esse mesmo desejo desaparece". ${ }^{25}$ Eis aí a única terapia à nossa disposição.

20 T. I, IV, iv, § 11.

21 T. I, IV, vii, § 7. Sobre essa tendência à autodestruição do entendimento, ver T. I, IV, i, do ceticismo quanto à razão.

22 Cf. T. I, IV, vii, § 3: "A memória, os sentidos e o entendimento são todos [...] fundados na imaginação, ou vividez de nossas ideias".

23 T. I, IV, vii, § 12.

24 T. I, IV, vii, § 14.

25 T. Introdução, § 9 . 
É preciso assinalar, ao mesmo tempo, que a questão da legitimidade das ficções oriundas da fantasia não possui o mesmo peso e sentido conforme abandonamos o Livro I, sobre as operações do entendimento, e avançamos para o Livro II, sobre as paixões, e, principalmente, para o Livro III, sobre a moral. ${ }^{26}$ Por exemplo, o problema da legitimidade das regras gerais da justiça passa a ser formulado do ponto de vista da utilidade..$^{27}$ De todo modo, essa mudança de perspectiva ganha sentido quando Hume anuncia o estilo de teoria que um cético pode edificar, a saber, um sistema filosófico que ganha força conforme vai avançando, ${ }^{28}$ sem que tenha de haver um porto seguro para o qual avançamos, que irá completar a pesquisa de uma vez por todas.

\section{III}

Além de Gilles Deleuze e Henry Allison, Peter Thielke também consegue desenvolver uma leitura fecunda do tema que nos ocupa a partir de uma perspectiva kantiana. ${ }^{29}$ A primeira ressonância apontada por Thielke entre a ficção natural e a ilusão transcendental encontra-se na escolha das metáforas. Nos capítulos finais da "Analítica Transcendental", Kant anuncia que acaba de percorrer a terra da verdade. Essa ilha está circundada "por um vasto e tempestuoso oceano, que é a verdadeira sede da ilusão, onde o nevoeiro espesso e muito gelo, em ponto de liquefazer-se dão a falsa impressão de novas terras". O pesquisador é descrito como um aventureiro de cujas aventuras "não poderá jamais desistir e tampouco levá-las a termo". ${ }^{30}$ A de Hume é notavelmente semelhante.

Sinto-me como um homem que, após encalhar em vários bancos de areia, e escapar por muito pouco do naufrágio ao navegar por um pequeno esteiro, ainda tem a

26 O termo moral, para Hume, significa os assuntos relativos aos homens, como no subtítulo do "Tratado". Aqui, mais especificamente, Hume está pensando na justiça, no governo, na economia etc.

27 O desenvolvimento dessa questão pede outro artigo. Digamos apenas que, na estética e na moral, as qualidades já apontadas da fantasia possuem uma positividade que as torna também corretivas. Por exemplo, há uma tese que já havia sido usada na Parte IV do Livro I, que será retomada no sistema moral e não será mais colocada sob suspeita. Ela diz que quando as contradições surgem na conversação, sentimos um desconforto (uneasiness) que a fantasia se encarrega de dissolver, ao forjar um ponto de vista artificial que encobre aquelas contradições e conserva a transição fácil na imaginação, fonte de prazer. Podemos, após essa operação, julgar moralmente. Ao mesmo tempo, só a fantasia disciplinada pela reflexão pode ser fonte de regras úteis. É a reflexão sobre as tendências das regras da fantasia de promover a estabilidade social que permite expulsar a superstição do corpo social. A superstição, ao contrário das regras de justiça, é frívola e inútil. Quando alguma ficção é admitida na teoria humeana sobre as instituições político-jurídicas, ela é uma ficção útil.

28 Cf. $T$, III, I, i, § 1.

29 Cf. Thielke, "Hume, Kant, and the sea of illusion".

30 CRP B 295. 
temeridade de fazer-se ao mar na mesma embarcação avariada e mal-tratada pelas intempéries, levando sua ambição a tal ponto que pensa em cruzar o globo terrestre em circunstâncias tão desfavoráveis. A memória de meus erros e perplexidades passados me faz desconfiar do futuro. A condição desoladora, a fraqueza e a desordem das faculdades que sou obrigado a empregar em minhas investigações aumentam minhas apreensões. E a impossibilidade de melhorar ou corrigir essas faculdades me reduz quase ao desespero, fazendo-me preferir perecer sobre o rochedo estéril em que ora me encontro a me aventurar por esse ilimitado oceano que se perde na imensidão. ${ }^{31}$

Evidentemente, a semelhança das metáforas não implica a semelhança das atitudes filosóficas. A atitude de Kant está mais próxima da do aventureiro que renova a embarcação para lançá-la novamente no oceano da ilusão. ${ }^{32} \mathrm{~A}$ de Hume, por sua vez, como vimos, é a de quem abandona a embarcação nas margens, avariada, e aplaca o desejo de novas aventuras. De acordo com Thielke, "mesmo que os erros da metafísica tradicional possam ser expostos quando reconhecemos o papel desempenhado pelas ilusões necessárias [da fantasia], a única resposta que Hume oferece é seu próprio 'ceticismo mitigado"". ${ }^{33}$ Ao contrário de Kant, não há nada semelhante a uma teoria do uso regulativo das ideias da razão em Hume. A partir desse uso regulativo, a ilusão transcendental, apesar de manter seu status de ilusão, não mais induz ao erro. O filósofo transcendental é capaz de mostrar que pode haver um uso legítimo da ilusão. No caso de Hume, entretanto, uma vez que as ficções da imaginação também dão origem a erros e absurdos, "a tentativa de evitar esses erros não nos conduz a lugar algum". ${ }^{34} \mathrm{O}$ que a história natural da filosofia pode mostrar é que as ficções são ficções e que só caímos vítimas delas quando nos tornamos dogmáticos, quando "não nos contentamos em saber as causas imediatas [dos fenômenos]; [mas] prosseguimos nossa busca até chegarmos ao princípio original e último". ${ }^{35}$

Essa aproximação não é sem obstáculos. Não há uma doutrina das faculdades em Hume. Consequentemente, não há uma teoria da razão como faculdade específica, sede de representações específicas, sede do incondicionado. Isso não quer dizer que haja uma deficiência na lógica das

$31 T$, I, IV, vii, § 1 .

32 Sabe-se que Kant irá encontrar não apenas ilusões, que poderão até ser reconsideradas do ponto de vista teórico, usadas do ponto de vista regulativo, mas novos usos para as ideias da razão: o uso prático da razão e a ideia de liberdade. A esse respeito, ver "Prolegômenos", Introdução, nota 2. Hume, diz aí Kant, com seu ceticismo corrosivo, afunda o barco da metafísica, mas assim perde de vista "o prejuízo positivo que resulta de tomar da razão as [vistas] mais importantes, baseadas nas quais ela pode impor à vontade o mais alto objetivo de todas as suas aspirações".

33 Thielke, op. cit., p. 82.

34 Ibid., p. 69.

$35 T$, I, IV, vii, § 5 . 
ficções humeana. Apenas aponta para o fato de que as diferenças entre Kant e Hume são tão importantes quanto as semelhanças entre eles. Como Thielke pôde perceber, a ilusão transcendental não encontra sua origem "no domínio empírico, mas somente na arena rarefeita da razão ilimitada". ${ }^{36}$ Apesar disso, Thielke não deixa de se embrulhar quando procura identificar antinomias na parte IV do Livro I do Tratado da natureza humana. Para tanto, seria preciso que Hume tivesse desenvolvido uma teoria da razão tal como a encontramos na "Dialética Transcendental". Como observa Allison, "não há antinomias no sentido kantiano em Hume, porque os conflitos nos quais a razão se encontra não são, para ele, internos à própria razão, mas [se dão] entre a razão e outras tendências da mente ou, de modo mais geral, entre a razão, considerada como faculdade autônoma [...] e a natureza humana como um todo". ${ }^{37}$

Allison também assinala que o termo ficção, no sentido de que nos ocupamos acima, é empregado como um termo técnico por Hume. Não se trata de simples erros, mas de uma tendência da imaginação, enquanto fantasia, de criar ou fabricar ideias e juízos a partir do material fornecido pelos sentidos. Segundo Allison, a ficção mais importante para Hume é a ficção isolada em T. I, IV, ii: a ficção da existência contínua e independente dos corpos. Isso porque, primeiro, a questão de sua gênese é nitidamente distinguida da questão de sua verdade ou falsidade, o que permite apreender melhor o que estamos chamando aqui de lógica da ficção. Ou seja, a ficção e o erro não devem ser confundidos. Em segundo lugar, isso permite ver o ponto a partir do qual a lógica da ficção se afasta da lógica da ilusão transcendental: a ficção da existência contínua e independente dos corpos conduz à crença na existência dos corpos, embora não tenhamos uma justificativa racional para essa crença. Dito de outra forma, para Hume nós inevitavelmente, seduzidos por tal ficção, acreditamos que os corpos possuem tal existência sem que disponhamos de uma prova cabal que pudesse estabelecer essa existência. Para Kant, o caso seria o de pensar os corpos como se eles possuíssem tal existência, embora soubéssemos que eles não a possuem. ${ }^{38}$ Daí a aproximação feita por Kant entre

36 Thielke, op. cit., p. 72. Thielke tem a prudência de informar que sua hipótese não sugere que Hume antecipa a posição de Kant na "Dialética Transcendental", mas "que a estrutura argumentativa referente à ilusão e ao erro em cada um deles é bastante similar" (p. 72).

37 Allison, "Custom and reason in Hume", p. 275. Ainda Segundo Allison, a busca pelas explicações completas do metafísico não conduz por si só, para Hume, "a conclusões aparentemente contraditórias (como é o caso para Kant); ao invés, ela põe a razão em conflito com outras tendências da mente" (ibid.). Isso não é nem um pouco trivial, porque explica, diz Allison, por que Kant escreve uma "Crítica da razão pura" para solucionar a contradição interna da razão consigo mesma, enquanto Hume apela para o descuido e para a distração, na conclusão do Livro I, como terapia contra os conflitos descritos naquele mesmo Livro do "Tratado".

38 Certo. Não é o caso. Para Kant, a ideia de Mundo só poderá ser usada como princípio regulativo do ponto de vista das sínteses progressivas, de modo assintótico. Fazemos aqui apenas uma aproximação visando à distinção entre regulação e crença. 
ilusão transcendental e ilusão de ótica. A lua parece maior quando emerge do horizonte, mas sabemos que ela não o é.

Sabe-se que, para Hume, nem mesmo a Geometria deixa de ser atravessada por ficções desse gênero. É o caso da ideia de igualdade perfeita. Também considerando a ideia de igualdade perfeita do ponto de vista genético, Hume observa que a "igualdade é uma relação [que] não é, estritamente falando, uma propriedade contida nas figuras mesmas, surgindo somente pela comparação que a mente faz entre elas". ${ }^{39}$ A comparação em questão é um juízo de proporção que opera precisamente com as ideias de maior, menor e igual. Ora, diz Hume, quando dois objetos se apresentam à nossa observação não temos como apontar um critério de igualdade infalível ou declarar, também de modo infalível, se eles são maiores ou menores uns em relação aos outros. "Nossos juízos nesses casos são tão passivos de dúvidas e erros quanto os juízos acerca de qualquer outro assunto". ${ }^{40}$ Para minimizar essas dúvidas e erros, utilizamos "uma medida comum e invariável" " para decidir a proporção precisa entre aqueles objetos. Embora Hume não o afirme, o caso aqui parece ser semelhante ao desenvolvido na parte IV do Livro I. Dessas dúvidas e erros, se segue, então, um desconforto (uneasiness) decorrente da correção de "nossa primeira opinião mediante uma revisão e uma reflexão". ${ }^{42}$ Como será o caso na seção i, parte IV, Livro I, do ceticismo quanto à razão, nossa razão ameaça se embrulhar em um mecanismo ostensivo de autocorreção cujo resultado poderá ser sua própria destruição. Porém, aqui também a natureza nos socorre, dissipando essas nuvens da razão.

[...] fazemos a suposição de um critério imaginário de igualdade que possa corrigir com exatidão tanto as aparências desses corpos como o procedimento de medição, reduzindo inteiramente as figuras a essa proporção. Tal critério é claramente imaginário. Porque como a própria ideia de igualdade é a de uma aparência particular corrigida por justaposição ou por uma medida comum, a noção de qualquer correção além daquela para a qual possuímos instrumentos ou uma técnica apropriada é uma mera ficção da mente, tão inútil quanto incompreensível. Entretanto, embora esse critério seja somente imaginário, a ficção é natural. ${ }^{43}$

Não é demais assinalar que essa ficção natural vem acompanhada de uma propriedade da imaginação que a literatura secundária tende a denominar de 
inércia. Logo a seguir à passagem acima, Hume descreve essa propriedade como bem usual e frequente. A mente tende a continuar a ação peculiar de preencher as lacunas decorrentes das dúvidas e erros dos juízos de nossos sentidos, "mesmo após ter deixado de existir a razão que originalmente a havia levado a começar". ${ }^{44}$ Nesse mesmo parágrafo dessa mesma seção, Hume ainda identifica essa tendência em outras áreas que não a Geometria: o músico que "prolonga o mesmo ato da mente", fabricando a ideia de intervalo musical completo "sem ser capaz de dizer de onde saiu seu critério"; o pintor, a partir das ideias de luz e sombra, e o mecânico, a partir das ideias de rapidez e lentidão, fabricam para as cores e para o movimento, respectivamente, critérios imaginados que permitirão criar comparações e igualdades exatas "para além do julgamento dos sentidos".

Falamos acima da fantasia como máquina de costurar o mundo. Dizer máquina de costurar é descrever a fantasia do ponto de vista dessa inércia. Essa propriedade da fantasia volta a aparecer em outras partes do "Tratado". Assim, em $T$, I, IV, ii, § 21, que também citamos acima, Hume cuida da distinção entre inferências baseadas "na coerência das aparições" e inferências baseadas na causa e no efeito. Essa última se funda no hábito ou costume e é "regulada pela experiência passada". No primeiro tipo de inferência, ao contrário, o que reina na mente é a irregularidade: atribui-se às aparências ou objetos uma coerência maior do que "a observada em nossas meras percepções". E, no parágrafo a seguir, Hume retoma a análise da parte II, Livro I, referente à Geometria.

Ao examinar o fundamento da matemática, observei que a imaginação, quando envolvida em uma cadeia de pensamentos, tende a dar continuidade a ela, mesmo na falta de seu objeto; e, como uma galera posta em movimento pelos remos, segue seu curso sem qualquer novo impulso. Afirmei ser essa a razão pela qual, após considerar diversos critérios aproximados de igualdade, e corrigi-los uns pelos outros, passamos a imaginar, para essa relação, um critério tão correto e exato que não é passível do menor erro ou variação. O mesmo princípio faz com formemos facilmente essa opinião da existência contínua dos corpos. ${ }^{45}$

É interessante notar que esse princípio da fantasia não é deixado sem explicação. Encontraremos a razão dessa tendência no Livro I, parte II, seção

44 Ibid.

$45 T$, I, IV, ii, § 22. Grifo nosso. Aqui, nessa mesma seção, esse princípio, tornado princípio da natureza humana, é também descrito como transição fácil, "progresso suave e ininterrupto da imaginação", "propensão a unir essas aparições fragmentadas mediante a ficção de uma existência contínua". Tendemos, diz ainda Hume, a eliminar a aparente descontinuidade entre nossas percepções por meio da fantasia de um ser contínuo. A criação de um ser contínuo - o mundo, é "capaz de preencher esses intervalos e preservar uma identidade perfeita e integral em nossas percepções". 
v, § 21. Hume indica a semelhança como "a fonte mais fértil de erros", como a relação "que mais facilmente produz um equívoco nas ideias", embora as outras relações de contiguidade e causalidade possam apenas "contribuir para esse mesmo efeito". Parece-nos que os erros e equívocos aqui devem ser entendidos por ficções da fantasia. Isso porque Hume diz que o leitor verá "vários exemplos disso no decorrer deste tratado". Ora, no contexto em que isso é afirmado, na mesma seção citada acima, a mesma tendência da fantasia é evocada: "continuamos com a mesma cadeia de pensamentos"; "temos uma forte tendência a confundir tais ideias [iguais ou semelhantes], tomando uma pela outra". A semelhança parece introduzir a inconstância nos outros princípios, tornando-os "princípios variáveis, fracos e irregulares". ${ }^{46}$ Por outro lado, nas expressões erro, equívoco e confusão, usadas por Hume para descrever essa tendência da mente, notamos aquela atitude ambígua do autor de que falamos, que decorre da passagem, na letra do texto, dos pontos de vista descritivo e genético para o ponto de vista normativo, da investigação que considera a natureza humana como ela é para a filosofia que a pensa como deve ser.

\section{IV}

É curioso que Deleuze afirme que, para Hume, estejamos imersos no delírio e que Allison faça uso frequente de noções psicanalíticas, como neurose e terapia, para comentar o objeto deste artigo nosso. Não é raro aparecerem textos na literatura secundária nos quais os nomes de Hume e de Freud são conjugados. ${ }^{47}$ Quanto a nós, quisemos partir de uma inspiração kantiana e mostrar um pouco da riqueza presente no tema das ficções naturais e inevitáveis tal qual Hume o desenvolve principalmente no Livro I, parte IV, do "Tratado da natureza humana". Lamentavelmente, Hume não volta mais a tratar dele, ao menos da mesma forma sistemática, nas obras de maturidade. ${ }^{48}$

$46 T, \mathrm{I}, \mathrm{IV}$, iv, $\S 1$.

47 Além do próprio Deleuze, Bento Prado Júnior e João Paulo Monteiro escreveram textos nos quais o pensamento de Hume e o de Freud são aproximados.

48 Kant também, na "Crítica da faculdade de julgar", quando estabelece uma nova modalidade de juízo, o juízo reflexionante, abandona a noção de ilusão transcendental. Quanto a Hume, esse sentido técnico de ficção que examinamos aqui desaparece da linha de frente da primeira "Investigação", por exemplo. Não há nenhuma seção a ela dedicada. Segundo Peter Thielke, do ponto de vista de Hume, a razão para isso está no fato de o tema ser muito difícil de domesticar - "the reason has more to do with the intractable problems illusion seems to raise [...] the topic of illusion simply posed too many problems" (Op. cit., p. 88n). Parece-nos que o caso é também o mesmo no que se refere a Kant. 


\section{Referências}

ALLISON, H. "Custom and reason in Hume: a Kantian reading of the first book of the Treatise". Oxford, Oxford University Press, 2008.

DELEUZE, G. "Hume". Tradução de Guido de Almeida. In: A ilha deserta e outros textos. São Paulo: Iluminuras, 2006.

HUME, D. "História natural da religião". Tradução de Jaimir Conte. São Paulo: Ed. UNESP, 2004.

. "Investigação sobre o entendimento humano". Tradução de José Oscar de Almeida Marques. São Paulo: Ed. UNESP, 1998.

. "Tratado da Natureza Humana". Tradução de Déborah Danowski. São Paulo: Ed. UNESP, 2001.

KANT, I. "Crítica da razão pura". Tradução de Valério Rohden e Udo B. Moosburger. São Paulo: Abril Cultural, 1983.

$\overline{\text { Cultura, }} 1984$.

. "Prolegômenos". Tradução de Tania Maria Bernkopf. São Paulo: Abril

THIELKE, P. "Hume, Kant, and the sea of illusion". Hume Studies, V. 29, Nr. 1, Apr. 2003. 